\title{
Spectral Estimation of Soil Properties in Siberian Tundra Soils and Relations with Plant Species Composition
}

\author{
Harm Bartholomeus, ${ }^{1}$ Gabriela Schaepman-Strub, ${ }^{2}$ Daan Blok, ${ }^{3}$ \\ Roman Sofronov, ${ }^{4}$ and Sergey Udaltsov ${ }^{5}$ \\ ${ }^{1}$ Centre for Geo-Information, Wageningen University, 6708 PB Wageningen, The Netherlands \\ ${ }^{2}$ Institute of Evolutionary Biology and Environmental Studies, University of Zürich, 8006 Zurich, Switzerland \\ ${ }^{3}$ Nature Conservation and Plant Ecology, Wageningen University, 6708 PB Wageningen, The Netherlands \\ ${ }^{4}$ Institute of Biological Problems of the Cryolithozone, 677980 Yakutsk, Russia \\ ${ }^{5}$ Institute of Physicochemical and Biological Problems of Soil Science, 142290 Pushchino, Russia
}

Correspondence should be addressed to Harm Bartholomeus, harm.bartholomeus@wur.nl

Received 13 February 2012; Accepted 18 June 2012

Academic Editor: Raphael Viscarra Rossel

Copyright ( 2012 Harm Bartholomeus et al. This is an open access article distributed under the Creative Commons Attribution License, which permits unrestricted use, distribution, and reproduction in any medium, provided the original work is properly cited.

\begin{abstract}
Predicted global warming will be most pronounced in the Arctic and will severely affect permafrost environments. Due to its large spatial extent and large stocks of soil organic carbon, changes to organic matter decomposition rates and associated carbon fluxes in Arctic permafrost soils will significantly impact the global carbon cycle. We explore the potential of soil spectroscopy to estimate soil carbon properties and investigate the relation between soil properties and vegetation composition. Soil samples are collected in Siberia, and vegetation descriptions are made at each sample point. First, laboratory-determined soil properties are related to the spectral reflectance of wet and dried samples using partial least squares regression (PLSR) and stepwise multiple linear regression (SMLR). SMLR, using selected wavelengths related with $\mathrm{C}$ and $\mathrm{N}$, yields high calibration accuracies for $\mathrm{C}$ and N. PLSR yields a good prediction model for $\mathrm{K}$ and a moderate model for $\mathrm{pH}$. Using these models, soil properties are determined for a larger number of samples, and soil properties are related to plant species composition. This analysis shows that variation of soil properties is large within vegetation classes, but vegetation composition can be used for qualitative estimation of soil properties.
\end{abstract}

\section{Introduction}

The Arctic is experiencing the highest rates of warming compared with other world regions [1] that will likely have great impacts on high-latitude ecosystems $[2,3]$. The large and potentially volatile carbon pools stored in Arctic soils have the potential for large emissions of greenhouse gases in the form of both $\mathrm{CO}_{2}$ and $\mathrm{CH}_{4}$ under warmer and potentially drier conditions, resulting in a positive feedback to global warming [4]. Further, climatic changes may impact vegetation development and affect water and energy exchange in tundra ecosystems, with consequences for permafrost thaw depth $[5,6]$ and concomitant soil carbon release to the atmosphere [7-9]. The response of soil organic matter decomposition to increasing temperature is a critical aspect of ecosystem responses to global change [10].
It has been suggested that a warmer and drier climate in Arctic regions might increase the decomposition rate and, hence, release more $\mathrm{CO}_{2}$ to the atmosphere than at present $[11,12]$.

Besides expected changes within the soil itself, changes on the vegetation development are observed and expected for future warming. Plant species composition may greatly affect rates of soil processes, including decomposition [13]. In general, species within a growth form (graminoids, evergreen shrubs, deciduous shrubs, and mosses) are more similar in their effects on decomposition than species belonging to different growth forms, with graminoid litter having the fastest rate and litter of deciduous shrubs and mosses having the slowest rates $[14,15]$. Gough et al. [16] found that soil pH was significantly correlated with plant species richness and density at larger spatial scales. 
Abiotic soil factors have a strong influence on vegetation development, since plant growth in tundra regions is typically limited by temperature and nutrient availability $[17,18]$. Without knowledge of the present chemical composition of the soil it is not possible to estimate how and with which magnitude vegetation changes will take place, thus limiting our understanding of climate-vegetationpermafrost feedbacks. Arctic vegetation is expected to be more shrub dominated with rising temperatures [18], which may positively feedback to summer atmospheric heating by decreasing the surface albedo $[19,20]$. On the other hand, an increase in shrub cover may concomitantly also lead to summer soil cooling and decreasing permafrost thaw by shading the soil surface [6], thus potentially slowing down soil carbon turnover. More knowledge on the relationships between soil properties and vegetation composition is however required to accurately predict the consequences of climate-induced vegetation shifts for soil carbon pools in the Arctic.

Due to the large carbon stocks in the permafrost soil and the potential high release of large quantities of carbon dioxide and methane, the role of tundra permafrost soils on global climate processes is significant. Therefore, we need to know how large the carbon content of the soil is, and how this varies in space. Furthermore, we need to determine other soil properties like $\mathrm{pH}$ and nutrients, in order to estimate how these may influence carbon turnover rates and vegetation development. However, costs for soil analysis are high and fieldwork faces many logistic difficulties due to the inaccessibility of the tundra areas.

Reflectance spectroscopy has proven to be a powerful tool for fast assessment of multiple soil properties [21,22] in both laboratory and field setups [23]. However, the applicability of reflectance spectroscopy relies on the construction of a calibration database, which is in general site specific. Although numerous papers have been published on the estimation of soil organic carbon and other soil properties in various environments [24], to our best knowledge none of them focused on highly organic tundra soil, and therefore no models are available to determine soil properties from their reflectance. Since bare soil surfaces occur rarely in tundra environments, the use of remotely sensed vegetation proxies will be essential for possible spatially continuous estimates of soil properties.

The objectives of this study are (1) to evaluate if reflectance spectroscopy operated in the field or in slightly controlled conditions can be successfully applied to assess soil properties that influence carbon turnover and vegetation development in a Siberian arctic tundra environment (2) to investigate the variation and distribution of major soil properties in this area, and (3) to investigate the relation between vegetation composition and soil properties of the organic layers and evaluate if plant species composition can be used as a proxy to estimate soil properties. We use reflectance measurements to calibrate partial least square regression (PLSR) models and stepwise multiple linear regression models (SMLR) for total C, total N, pH, total K, total P, and soil moisture. Selected models with a good performance are then applied to estimate properties for a larger number of soil samples. Finally, the relations between soil properties, and their relation with plant species composition are discussed.

\section{Materials and Methods}

2.1. Site Description and Measurements. Measurements are made in a low-Arctic tundra site within the Kytalyk nature reserve in North East Siberia, Russia $\left(70^{\circ} 49^{\prime} \mathrm{N}, 147^{\circ} 28^{\prime} \mathrm{E}\right)$. The research site covers an area of ca $9 \mathrm{~km}^{2}$ and is located on the north bank of the Berelekh (Yelon) river, a tributary of the Indigirka river, approximately $30 \mathrm{~km}$ north West of the town Chokurdakh. The study area consists of a floodplain area along the river and an extensive plain with thaw lakes and drained thaw lakes. The only large elevation difference (ca $20-30 \mathrm{~m}$ ) is caused by the presence of a Pleistocene river terrace. The mean annual air temperature is $-10.5^{\circ} \mathrm{C}$, with a mean January temperature of $-34.2^{\circ} \mathrm{C}$ and a mean July temperature of $+10.4^{\circ} \mathrm{C}$. Annual mean precipitation amounts to $212 \mathrm{~mm}$, of which about half falls as snow [25]. The soil is frozen for most part of the year, but the permafrost thaws to max. $50 \mathrm{~cm}$ depth during summer. Although there are only minor differences in topography in the area, there is a large variation in micro topography and hydrology, which results in a large variation in vegetation types. The vegetation at the research site consists of a mixture of graminoids, forbs, mosses, and shrubs and is classified as G4 (tussock-sedge, dwarf shrub, and moss tundra) and S2 (low-shrub tundra) on the Circumpolar Arctic Vegetation Map (CAVM) [26]. Fieldwork is done in the summer of 2008, including spectral measurements of soil and vegetation, combined with the collection of soil samples and vegetation descriptions.

\subsection{Methodology}

2.2.1. Soil Description and Sampling. Soil sampling is done in two ways to get a good impression of the differences and spatial variation in soil properties and types. First, soil profile descriptions are made along short transects (ca 2$9 \mathrm{~m}$ length), to study the variation in soil profile under the dominating plant functional types. This is done for three locations: transect 1 is located on the Pleistocene river terrace, transect 2 on the slope down from this terrace towards the drained thaw lake, and transect 3 is located in the drained thaw lake (Figure 1). The soil is described down to the frozen layer (horizons and thickness, texture, decomposition stage, Munsell color), and for one location within each transect a permafrost drill is used to sample frozen layers. Second, soil samples are collected for 37 plots throughout the area. Sampling is done randomly within the different main vegetation types, ensuring a comparable number of samples for all main vegetation types. For these plots, the thickness of the decomposed (no plant fibers visible anymore) and slightly decomposed (plant remains still observable) organic layer is measured and samples are collected for spectral analysis. All samples $(N=128)$ are air-dried to determine the moisture content and prepare them for laboratory spectral measurements. Vegetation descriptions are made in the plots where soil samples are collected, whereby we noted species identities and estimated plant fractional cover.

2.2.2. Spectral Measurements and Laboratory Element Analysis. The spectral reflectance of the soil samples is measured 


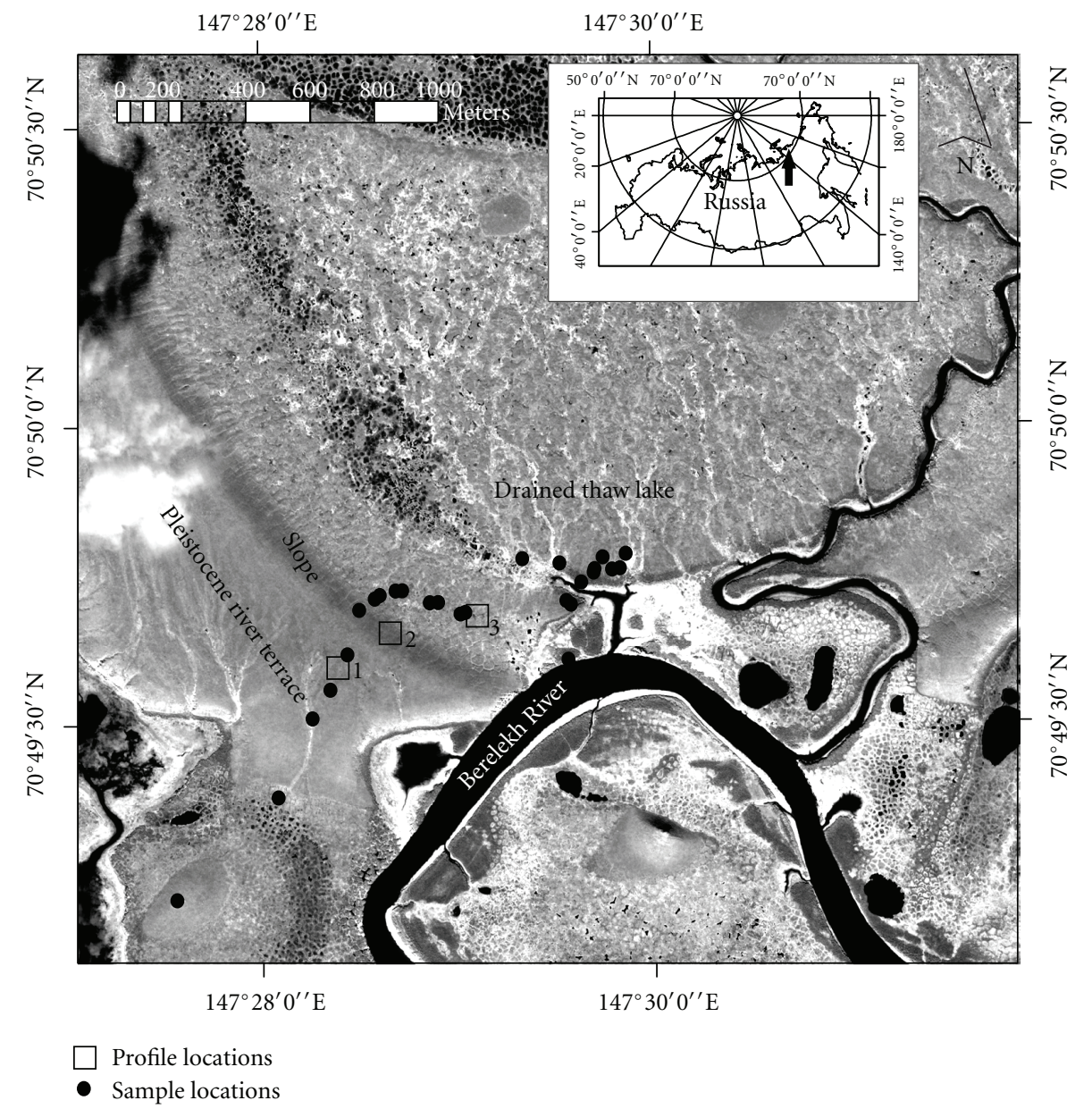

Figure 1: Panchromatic GeoEye-1 image with an overview of the study area including the locations of the profile descriptions and sample locations. The arrow on the overview map indicates the location of the study area in Russia.

with an ASD Fieldspec Classic FR, ranging from 350$2500 \mathrm{~nm}$, combined with an ASD contact probe. A white spectralon calibration panel is used as reference. For most samples this is done under field conditions $(N=118$, further referred to as fieldspectra), although this was not possible for 10 samples originating from the frozen mineral soil. For all samples $(N=128)$, the moisture content is determined by weighing the fresh and air dried samples. Additionally, the reflectance of the air dried samples is measured (further referred to as labs pectra). The frozen samples are included in this dataset, after defreezing and drying them. Part of the soil samples $(N=38)$ are sent to the laboratory (Inst. Of Physicochemical and biological Problems in Soil Science, Pushchino) for chemical analysis. To ensure that the full range of full properties is represented, these samples are selected in such a way that samples from all horizons, landscape elements, and from under all main vegetation types are included. Organic soil samples $(\mathrm{N}=33)$ are analyzed for $\mathrm{pH}$, Total P, K, N, and C, while the mineral soil samples $(N=5)$ are additionally analyzed for $\mathrm{Mg}, \mathrm{CaO}$, and $\mathrm{Fe}_{2} \mathrm{O}_{3}$.

Different regression methods are used to relate the chemical analysis to the spectral measurements. As a reference technique, we use Partial Least Square Regression (PLSR) for all soil properties (Total C, Total $\mathrm{N}, \mathrm{pH}$, Total $\mathrm{P}$, and Total $\mathrm{K}$ and moisture). This method has been used frequently to develop soil property models to determine, for example, organic carbon in laboratory, field and airborne settings [27-29]. PLSR is done in Parles [30], where all reflectance spectra are converted to apparent absorbance, mean centre transformation is done, and spectra are denoised using a Savitzky-Golay filter. Models are evaluated by leave-one-out cross validation, using the root mean square error (RMSE) and Akaike Information Criterion (AIC) to select the proper number of latent variables.

Furthermore, we investigate the possibility to use known absorption features in the reflective domain to estimate soil carbon and nitrogen. Because the samples are highly organic, we assume that absorption features related to carbon and nitrogen in plant material (e.g., in components like lignin and cellulose) can still be observed in the soil reflectance spectra. Therefore, we use the carbon-and nitrogen-related wavelengths described by Curran [31] in combination with stepwise multiple linear regression (SMLR) for the estimation of Total $\mathrm{C}$ and Total $\mathrm{N}$ in the soil samples. Regression models are fitted for lab spectra and field spectra and evaluated by means of leave-one-out cross validation, using 
the $R$ software package [32]. Model performance is evaluated using the $R^{2}$, RMSE, and ratio of performance to deviation (RPD), according to the criteria defined by Chang and Laird [33]. If appropriate prediction models can be established, soil properties are estimated for all soil samples. This results in a full analysis of all described soil profiles and an analysis of the slightly decomposed and strongly decomposed organic layers for the 37 locations for which full vegetation description is done.

Due to the continuous vegetation cover, nondestructive measurements of soil reflectance are not possible. Since plant species composition is related to abiotic factors and are a potentially important source of variation in soil processes, including decomposition rates [13], we investigated the relation between plant species composition and soil properties. The vegetation descriptions are classified into four major plant functional types (dry tussock evergreen shrub, deciduous shrub, moist Sphagnum sedges, and wet sedge pools), using the two-way indicator species analysis (TWINSPAN) for Windows v2.3 [34] as described in Blok [35]. Boxplots of physical and chemical soil properties per vegetation class are made to investigate the relation between soil properties and vegetation type.

\section{Results and Discussion}

3.1. Soil Profiles and Chemical Properties. Soil profile descriptions made for three short transects are shown in Figure 2. Within each transect, the microtopography and active layer thickness are measured at fixed distances of $10 \mathrm{~cm}$, and at representative locations in terms of vegetation composition the full profile is described. The depth from the horizontal plane, shown on the $y$-axis, is the relative height compared to the highest point within the corresponding profile. Because of the presence of permafrost within the first meter, all soils are classified as Gelisol according to the USDA soil taxonomy. On the Pleistocene ridge (transect 1), the soils consist of an organic layer on top of clayey/silty parent deposits. The organic layer can mostly be subdivided in an O horizon, followed by an Ao horizon with decomposed organic material. On some locations, an Oi horizon is visible, with slightly decomposed organic material. The presence of an $\mathrm{O}$ horizon depends on the vegetation type (e.g., Eriophorum vaginatum hummocks) and hydrological conditions (e.g., wet conditions with Sphagnum (peat mosses)). Organic layer thickness mostly varies between 5 and $15 \mathrm{~cm}$, but occasionally thicker layers occur (up to $25 \mathrm{~cm}$ ). The mineral B horizon consists of clay/loamy clay, with an olive to dark olive grey color and continues beyond our maximum sampling depth $(92 \mathrm{~cm})$. Spots of iron oxidation can be seen in the thawed soil, which indicates that aerobic processes do occur above the permafrost. The total $\mathrm{C}$ content of the mineral soil lies between $1.97 \%$ and $4.86 \%$. The higher $\mathrm{C}$ content is found at a depth of $>60 \mathrm{~cm}$ and is caused by some small organic remains. The soil profiles in transect 2 , on the slope of the Pleistocene ridge to the drained thaw lake basin, shows no large differences with transect 1 on top of the ridge, although thick $\mathrm{O}$ horizons are absent. The mineral B horizon has the same texture as on the ridge, and oxidation marks are
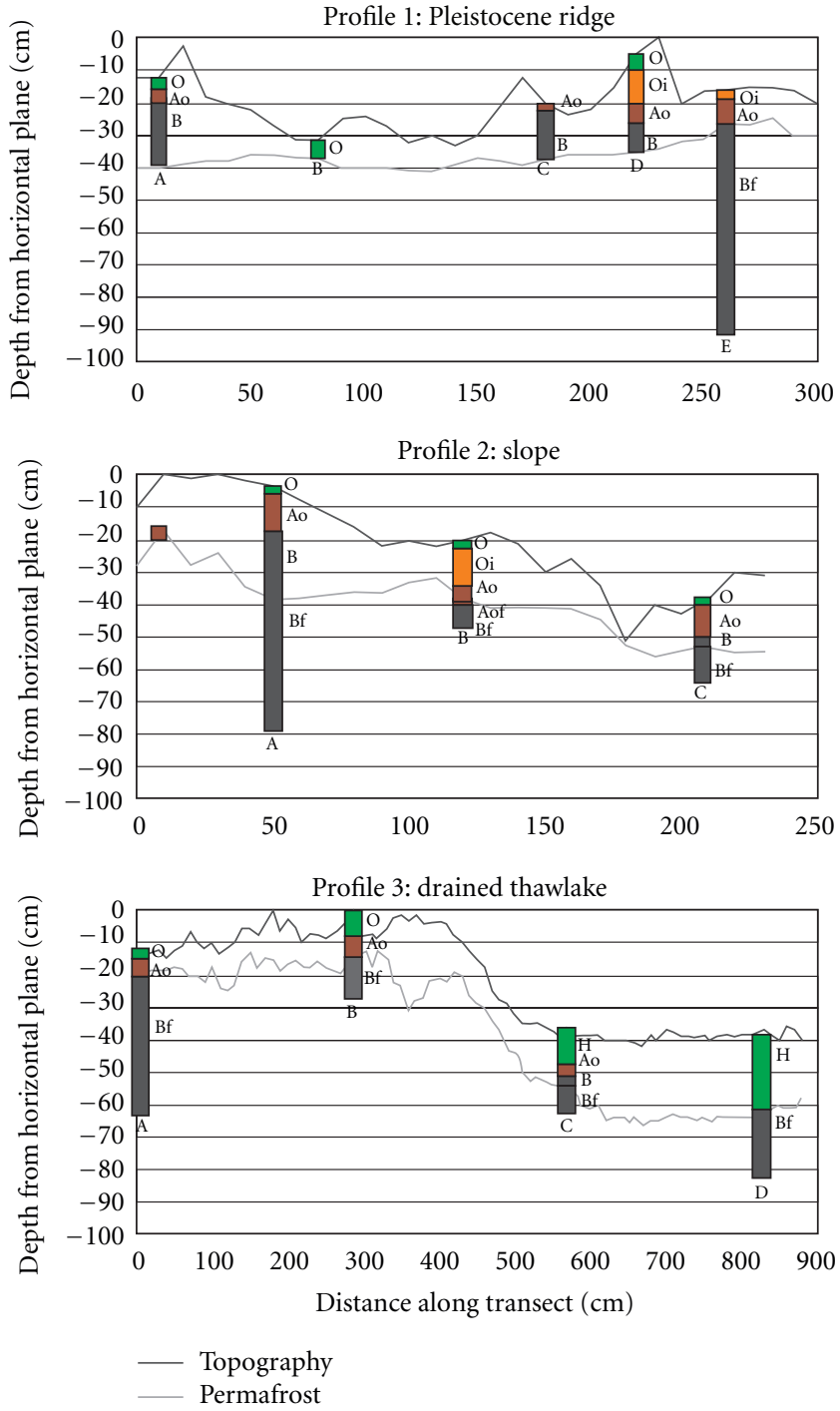

FIGURE 2: Soil profile descriptions along three transects (green = organic material, orange slightly decomposed organic = soil, brown $=$ decomposed organic soil, and grey $=$ mineral soil). Names of occurring plant species are given in the Appendix, including the estimated fractional cover.

observed. The profiles in the drained thaw lake basin differ from the other locations by the absence of an Oi horizon. Either a small organic layer is present at the drier locations, or a thick wet organic layer ( $\mathrm{H}$ horizon) is present at the lower parts. Usually, a small organic layer with decomposed material is found between the organic layer and the mineral B horizon, only the profile on the location with Sphagnum lacks this Ao horizon. At the time of sampling, the top of the permafrost follows the top of the mineral soil, which suggests that permafrost thaw is related to the soil composition or vegetation composition.

The soil sampling of the $\mathrm{B}$ horizon down to a maximum depth of $92 \mathrm{~cm}$ reveals an average carbon content of $2.84 \%$ in the frozen mineral soil along all transects, with a maximum value of $4.86 \%$ on the Pleistocene ridge. Compared to 
TABLE 1: Summary of chemical analysis and correlations $(R)$ between soil properties.

\begin{tabular}{lccccc}
\hline & $\mathrm{pH}$ & Total P $(\mathrm{mg} / 100 \mathrm{~g})$ & Total K $(\mathrm{mg} / 100 \mathrm{~g})$ & Total N $(\%)$ & Total C (\%) \\
\hline Min & 3.88 & 62 & 195 & 0.29 & 1.97 \\
Max & 6.78 & 201 & 1700 & 2.16 & 44.66 \\
Mean & 4.92 & 129 & 860 & 1.07 & 20.75 \\
Stdev & 0.66 & 38.23 & 426.16 & & 11.47 \\
\hline $\mathrm{pH}$ & 1 & & & & \\
Total P & -0.29 & 1 & 1 & 1 & 1 \\
Total K & 0.63 & -0.62 & -0.89 & 0.88 & 1 \\
Total N & -0.45 & 0.72 & -0.97 & & \\
Total C & -0.62 & 0.60 & & & \\
\hline
\end{tabular}
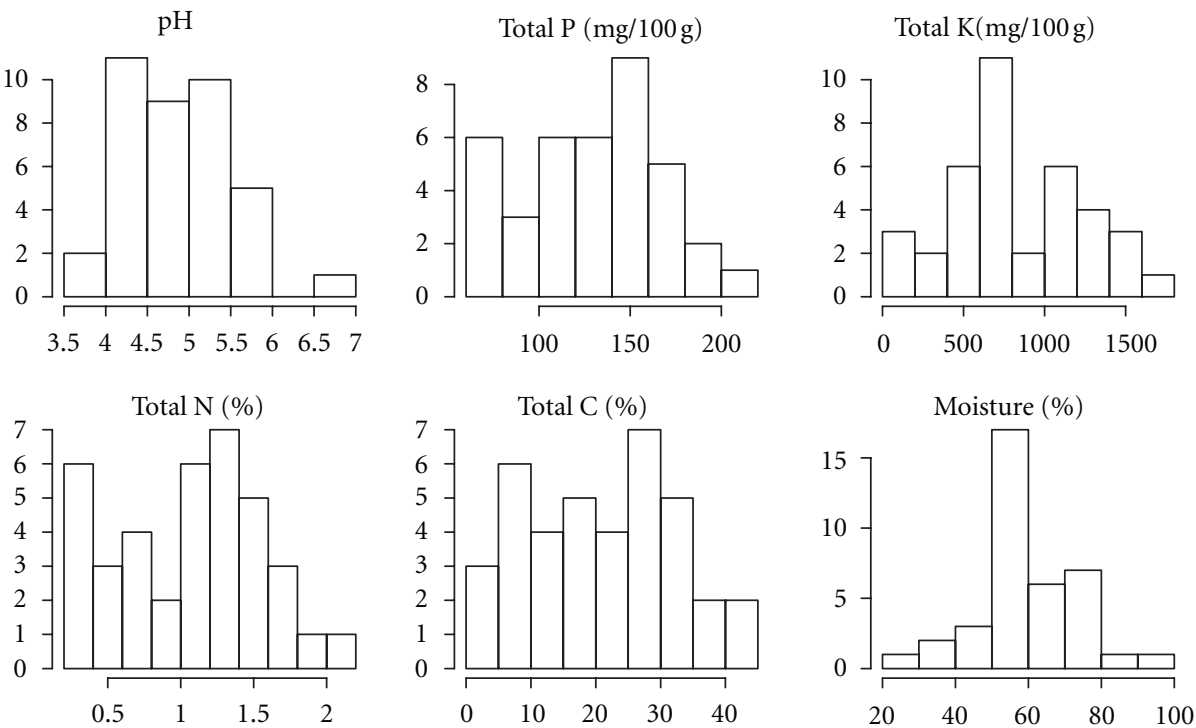

FIGURE 3: Frequency histograms of the 38 analyzed soil samples. The $x$-axis shows the ranges of the soil property and the $y$-axis the frequency.

an average $\mathrm{C}$ content of $2.56 \%$ in Yedoma soils [36], our site shows slightly higher $\mathrm{C}$ contents for the sampled depth. This means that an increase in active layer thickness will expose a slightly higher amount of $\mathrm{C}$ to decomposition than estimated by Zimov et al. [36].

In general, very large differences in soil composition are observed at short distances, making continuous spatial mapping of soil properties a difficult task. The strong spatial variation in soil composition corresponds with the spatial variation in microtopography, surface hydrology, and plant species composition. For example, thickness of the organic layer can vary between 5 to $25 \mathrm{~cm}$ within a distance of less than a meter.

Table 1 shows the statistical summary of laboratory analysis and correlations between soil properties. The values show that the ranges in all soil properties are large and that variation is high. Soils are in general acid, although in some cases neutral $\mathrm{pH}$ levels were measured. As expected the Total C content is high on average, with lower levels for the mineral soil. Total $\mathrm{K}$ and total $\mathrm{C}$ show a very high correlation $(R=-0.97)$, and both properties are clearly correlated with total $\mathrm{N}(R=0.88$ with total $\mathrm{C}$ and $R=-0.89$ for total $\mathrm{K})$. Total $\mathrm{P}$ and $\mathrm{pH}$ are not strongly correlated with any of the other soil properties. Frequency histograms are shown in Figure 3, which show that the selection of samples for chemical analysis was done well, since the full range of all soil properties is nicely covered.

3.2. Soil Spectral Analysis. In general, the mineral soil has the lowest reflectance when measured in the laboratory (Figure 4). Major absorption features around 1400 and $1900 \mathrm{~nm}$ are caused by remaining water in the samples. The slightly decomposed horizons show a higher reflectance in the near infrared and more pronounced water absorption features. First derivatives emphasize the presence of small absorption features at $1535 \mathrm{~nm}$, between 1700 and $1800 \mathrm{~nm}$ and between 2200 and $2320 \mathrm{~nm}$, which correspond with absorption features for plants, caused by the presence of lignin, starch, cellulose, nitrogen, and proteins [31]. The absorption features are most pronounced in the slightly decomposed samples, but present in the decomposed samples as well. In the mineral soil spectra, an absorption feature around $2200 \mathrm{~nm}$ is present, caused by the fact that clay is the parent material [37], but also the organic layers do show a minor absorption feature at this wavelength. Field observations revealed the presence of iron oxides in 


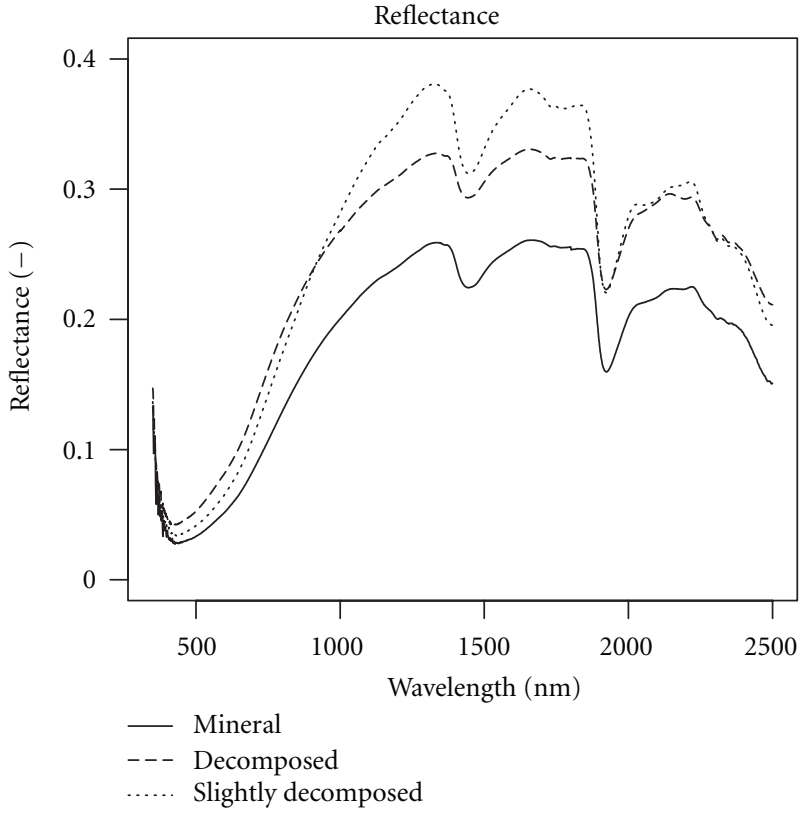

(a)

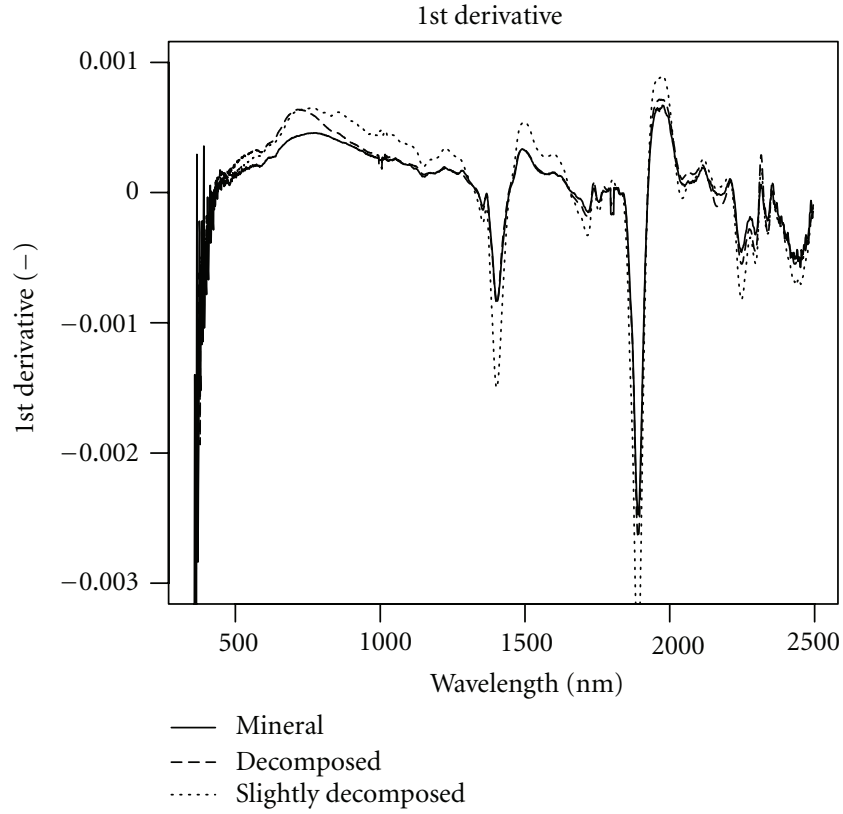

(b)

FIGURE 4: Spectral signatures of three horizons sampled at the same geographic location. The left graph shows the reflectance spectra, the right figure shows the first derivative of the reflectance spectra.

TABLe 2: Performance of model fits using lab spectra of dried samples, evaluated with leave-one-out cross-validation.

\begin{tabular}{lcccccccc}
\hline & $\mathrm{pH}$ & Total P $(\mathrm{mg} / 100 \mathrm{~g})$ & Total K $(\mathrm{mg} / 100 \mathrm{~g})$ & Total N $(\%)$ & Total N $(\%)$ & Total C $(\%)$ & Total C $(\%)$ & Moisture $(\%)$ \\
\hline Method & PLSR & PLSR & PLSR & PLSR & SMLR & PLSR & SMLR \\
\hline No. of factors & 5 & 2 & 2 & 8 & 2 & 2 & 9 & PLSR \\
$R^{2}$ & 0.50 & 0.38 & 0.79 & 0.73 & 0.80 & 0.79 & 0.95 & 0.42 \\
RMSE CV & 0.47 & 29.77 & 193.92 & 0.26 & 0.23 & 5.17 & 2.59 & 10.09 \\
RPD CV & 1.42 & 1.28 & 2.20 & 1.93 & 2.18 & 2.22 & 4.43 & 1.33 \\
\hline
\end{tabular}

RMSE CV: root mean square error of cross-validation, RPD CV: ratio of performance to deviation of cross-validation, PLSR: partial least squares regression, SMLR: stepwise multiple linear regression.

the mineral soil, which was supported by the chemical analysis. However, the spectral signature of the mineral soil shows no clear absorption feature for iron oxides.

Using the lab spectra, good calibrations are found for Total K and Total C, using PLSR (Table 2). The good fit for Total $\mathrm{K}$ is mainly caused by the strong correlation with Total C and Total N (Table 1), instead of specific absorption features by K. The PLSR model for Total $\mathrm{N}$ yields somewhat lower results with a $R^{2}$ of 0.75 and RPD of 1.97 , which just classifies it as a moderate model for prediction, but 8 factors are used to fit this model. This is relatively high, given the size of the calibration data set. For $\mathrm{pH}$ a moderate model (class $\mathrm{B}$ according to the classification of Chang and Laird [33]) model can be fitted for prediction as well, but with a RPD of 1.42 this model is on the lower level of this class, indicating that the predicted $\mathrm{pH}$ values should rather be interpreted qualitatively than quantitatively. Total $\mathrm{P}$ cannot be predicted well from the spectral data. The RPD of 1.28 and $R^{2}$ of 0.38 indicate that this PLSR model cannot reliably be applied on other soil spectra.
SMLR using the absorption features described by Curran [31] yields very good results for the prediction of total $\mathrm{N}$ and total C (Table 2). Especially for total,C the estimations improve strongly, to an RMSE of $2.59 \%$; half of the RMSE was achieved by the PLSR model, which is also expressed with a high $R^{2}(0.95)$ and RPD (4.43). It has to be noted that the number of wavelengths that are kept for the final multiple linear regression model is rather high for total C, which may limit the use of this model for other areas. The RMSE is larger than results obtained in other studies [24], but is very acceptable given the range in the dataset and high levels of total C in this study. For total N, the model performance also improves, although less stronger than for total C, but next to that the number of factors used in the regression is largely reduced. Because total $\mathrm{K}$ has a very strong correlation with Total $\mathrm{C}$ we checked if an indirect estimation of Total K, using the predicted Total $\mathrm{C}$ values and relation between the two properties, yields a better prediction. This is not the case, but results are comparable with the values obtained with PLSR on the spectra directly. Scatterplots of the observed versus 
TABLE 3: Performance of model fits using spectra of samples under field conditions, evaluated with leave-one-out cross validation.

\begin{tabular}{|c|c|c|c|c|c|c|c|c|}
\hline & $\mathrm{pH}$ & Total P (mg/100g) & Total K (mg/100g) & Total N (\%) & Total N (\%) & Total C (\%) & Total C (\%) & Moisture (\%) \\
\hline Method & PLSR & PLSR & PLSR & PLSR & SMLR & PLSR & SMLR & PLSR \\
\hline No. of factors & 4 & 2 & 2 & 2 & 4 & 4 & 8 & 1 \\
\hline$R^{2}$ & 0.45 & 0.16 & 0.44 & 0.34 & 0.43 & 0.45 & 0.74 & 0.11 \\
\hline RMSE CV & 0.48 & 34.93 & 314.73 & 0.40 & 0.39 & 8.38 & 6.03 & 12.7 \\
\hline RPD CV & 1.35 & 1.09 & 1.35 & 1.24 & 1.28 & 1.37 & 1.90 & 1.05 \\
\hline
\end{tabular}

RMSE CV: root mean square error of cross validation, RPD CV: ratio of performance to deviation of cross validation, PLSR: partial least squares regression, SMLR: stepwise multiple linear regression.

TABLE 4: TWINSPAN vegetation classes and dominant plant species per class.

\begin{tabular}{ll}
\hline TWINSPAN class & Dominant plant species \\
\hline Dry tussock evergreen & Ledum decumbens, Eriophorum vaginatum, Salix glauca, and Vaccinium uliginosum \\
Moist deciduous shrub & Betula nana, Salix pulchra, and Arctagrostis latifolia \\
Moist Sphagnum sedge & Spagnum spp, Carex aquatilis, and Salix fuscescens \\
Wet sedge pools & Eriophorum angustifolium \\
\hline
\end{tabular}

predicted values for the best performing methods are shown in Figure 5.

Using fieldspectra (i.e., wet soil samples) the model performance decreases drastically, mostly to levels that are not acceptable for quantitative prediction of soil properties $(\mathrm{RPD}<1.4)$. Only for total $\mathrm{C}$ a reasonable model could be fitted, using SMLR, but the RMSE is more than two times larger than the RMSE found for dried samples. This accuracy is comparable with the results using fieldspectra only of Knadel et al. [38], for their study site in Denmark, which shows comparable ranges in carbon. The difference in accuracy between labs pectra and fieldspectra is very likely related to soil moisture, which generally decreases the prediction capabilities of visible and near infrared spectroscopy. Interestingly, the moisture content cannot be estimated from the fieldspectra using PLSR ( RPD $=1.05$, Table 3), but using the dried spectra some correspondence can be found with the reflectance measurements (RPD = 1.33, Table 2). The low accuracy for soil moisture is most probably caused by the very high levels of soil moisture (20$95 \%)$. Since the absorption features that are related to water may saturate at lower moisture levels already, observing differences between these high levels is not possible from the reflectance spectra.

3.3. Soil Properties per Horizon. The identified models for lab spectra are used to predict soil properties for all samples collected at the 37 locations for which detailed vegetation descriptions are done and all samples collected from the soil profiles. Box plots of $\mathrm{pH}$, total $\mathrm{K}$, total $\mathrm{C}$, and total $\mathrm{N}$ are made for the different horizons (Figure 6). Total $\mathrm{K}$ and $\mathrm{pH}$ show a gradual increase when going deeper into the soil. The content of total $\mathrm{C}$ and total $\mathrm{N}$ decreases with depth. There are clear differences in the median and quartile values for the different horizons, although there is overlap in the minimum and maximum ranges. Further, there is a large variation in all soil properties within the slightly decomposed and decomposed layer, as can be seen from the width of the boxes, showing the $25 \%$ and $75 \%$ quantile ranges (Figure 6). Only for the mineral soil the variation is more constrained for all soil properties. The levels of total $\mathrm{C}$ in the organic layers are comparable to those presented by Michaelson et al. [39] for the Coastal Plain and Northern Foothills in Alaska, but the mineral soil samples in their study show a larger variation in observed values, due to the large geographic extent of their study.

With the data we gathered, it is not possible to assess the total carbon stock of our research site. To make such predictions the maximum soil sampling depth should be increased and bulk density has to be determined for each sample. Under current conditions, the total organic layer is thawed early in the summer season, but on a gram per carbon basis deep permafrost mineral soils show carbon release raters similar to organic soils for some soil types [40]. Further, changes in hydrology will have a large influence on carbon decomposition as hydrological conditions determine if the carbon fluxes to the atmosphere are released under aerobic (mainly $\mathrm{CO}_{2}$ ) or anaerobic (high $\mathrm{CH}_{4}$ rates) conditions. According to Lee et al. [40], aerobic conditions have a greater effect on climate when compared with a similar amount of permafrost thawing in an anaerobic environment.

3.4. Relation between Soil Properties and Vegetation Type. The twinspan classification results in four vegetation classes, for which the dominant plant species are given in Table 4 . Figure 7 shows boxplots of the predicted soil properties for the vegetation classes. Separate boxplots are made for the slightly decomposed layer (Oi horizon) and the decomposed organic layer (Ao horizon).

The average $\mathrm{pH}$ of the soil is comparable for all vegetation types, but the variation within the plant communities shows large differences. The dry tussock evergreen shrub and the wet sedge pools, dominated by Eriophorum angustifolium, show a large variation in $\mathrm{pH}$ of the slightly decomposed organic layer. For the moist Sphagnum sedge vegetation, the $\mathrm{pH}$ in the slightly decomposed horizon hardly varies. 

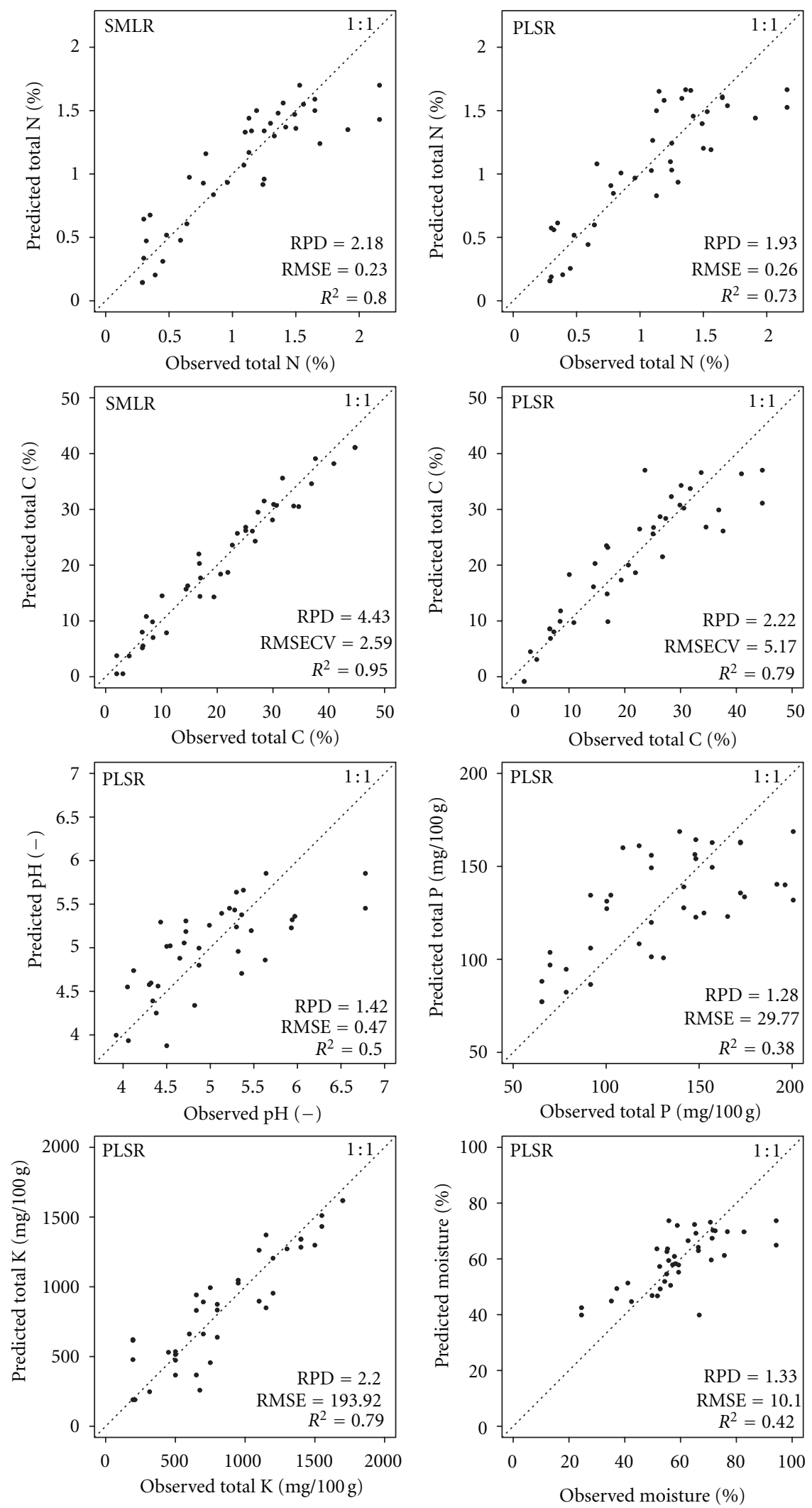

FIGURE 5: Scatterplots of the observed versus predicted values for multiple soil properties, based on PLSR or SMLR using lab spectra. 

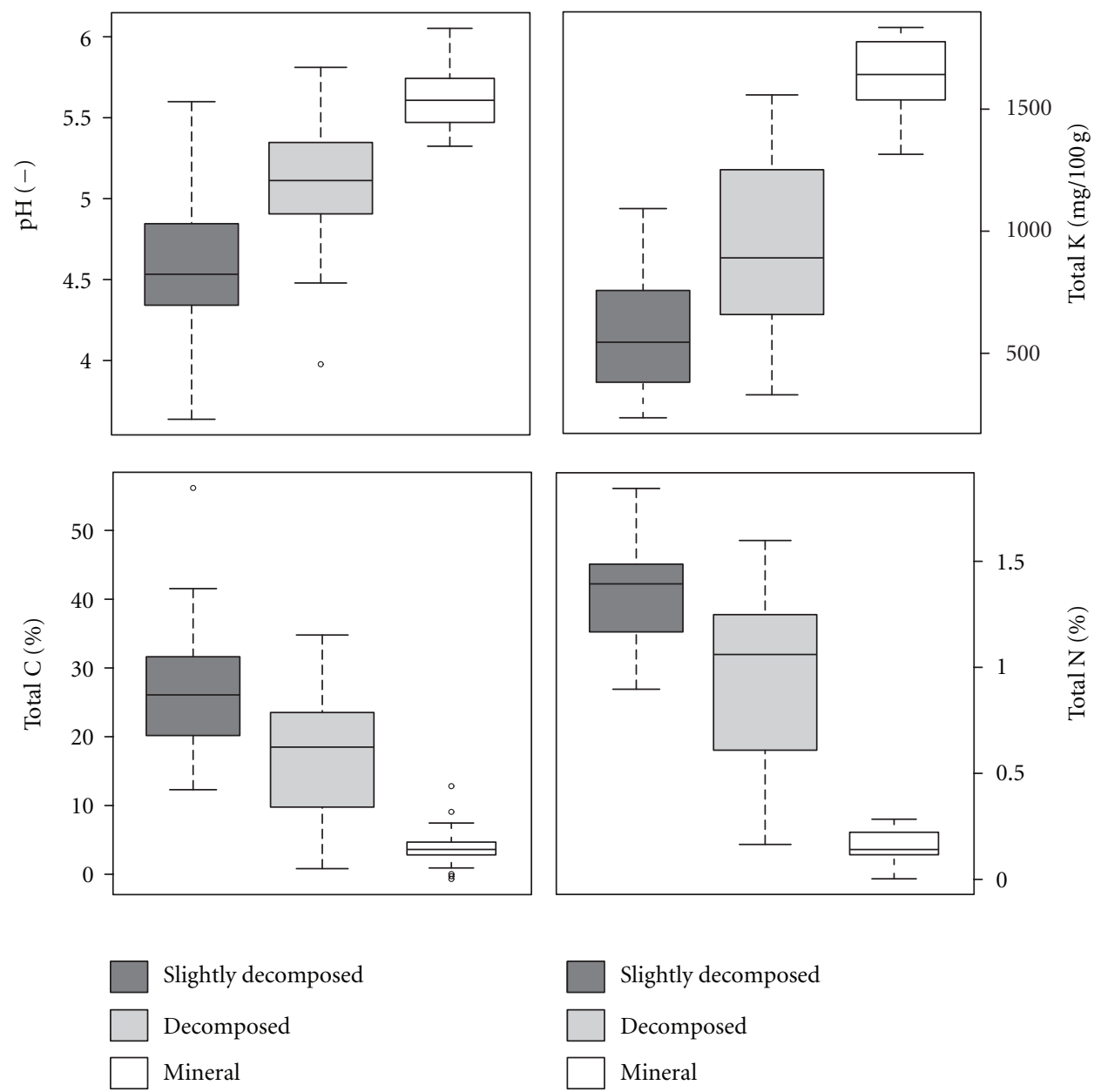

Slightly decomposed

Decomposed

Mineral

Figure 6: Boxplots for $\mathrm{pH}$, total K, total $\mathrm{C}$, and total N, based on PLSR ( $\mathrm{pH}$ and $\mathrm{K}$ ) and SMLR (C and N) estimated soil properties, for all the samples.

The soil in the decomposed organic layer is on average less acid, with a slightly higher $\mathrm{pH}$ for the moist Sphagnumsedge vegetation, compared to other vegetation types. The observed $\mathrm{pH}$ values correspond well with values in literature [16]. Soils under all vegetation types are more acidic than the optimal pH for methanogenesis of around 6 [41], but methanogenesis has been shown to occur at low $\mathrm{pH}(\mathrm{pH}=$ 3.1) [42]. Plant growth in the tundra system can be limited by a number of factors, such as soil temperature and nutrient availability. The measures of nutrients do not indicate direct deficiencies, but if $\mathrm{pH}$ is lower than $6, \mathrm{P}$ starts forming insoluble compounds with iron $(\mathrm{Fe})$ and aluminium $(\mathrm{Al})$. Concentrations of $\mathrm{N}$ are less sensitive to $\mathrm{pH}$, but efficient use by plants depends on availability of several nutrients. Therefore, the amounts of nutrients available for plant growth is probably limited by soil $\mathrm{pH}$, in combination with low decomposition activity due to low temperatures and low quality of organic material.

The total C content of the slightly decomposed layer is in general higher than for the decomposed layer. Furthermore, total $\mathrm{C}$ in the upper layer shows more variation for the different plant communities. Most vegetation types showed large differences in total $\mathrm{C}$ content between the slightly decomposed and decomposed layer. The sedge dominated tussock/evergreen shrub class is characterized by large amounts of standing litter and dense roots, which causes the high amount of total $\mathrm{C}$ in the slightly decomposed layer. Also the thickness of the organic layer shows large variation within the different vegetation classes. On average, the total organic layer is the thinnest under the deciduous shrubs. Combined with the fact that the total C content is relatively low, this vegetation type may contribute least to soil carbon stocks in the arctic tundra. However, large aboveground shrub biomass can also constitute a significant carbon pool, thus contributing to the total carbon stock in shrub tundra areas. Several studies suggest that an increase in temperature will lead to an increase in shrub growth in arctic tundra [17, 18, 43-45]. This implies that the future total $\mathrm{C}$ accumulation in tundra soils will decrease, since the thickness of the organic layers will on average decrease and the total $\mathrm{C}$ content is not higher than for other vegetation types. However, there will be a trade off with the fact that increased abundance of deciduous shrubs with future climate warming will promote carbon storage, because of their relatively large allocation to woody stems that decompose slowly [14]. 

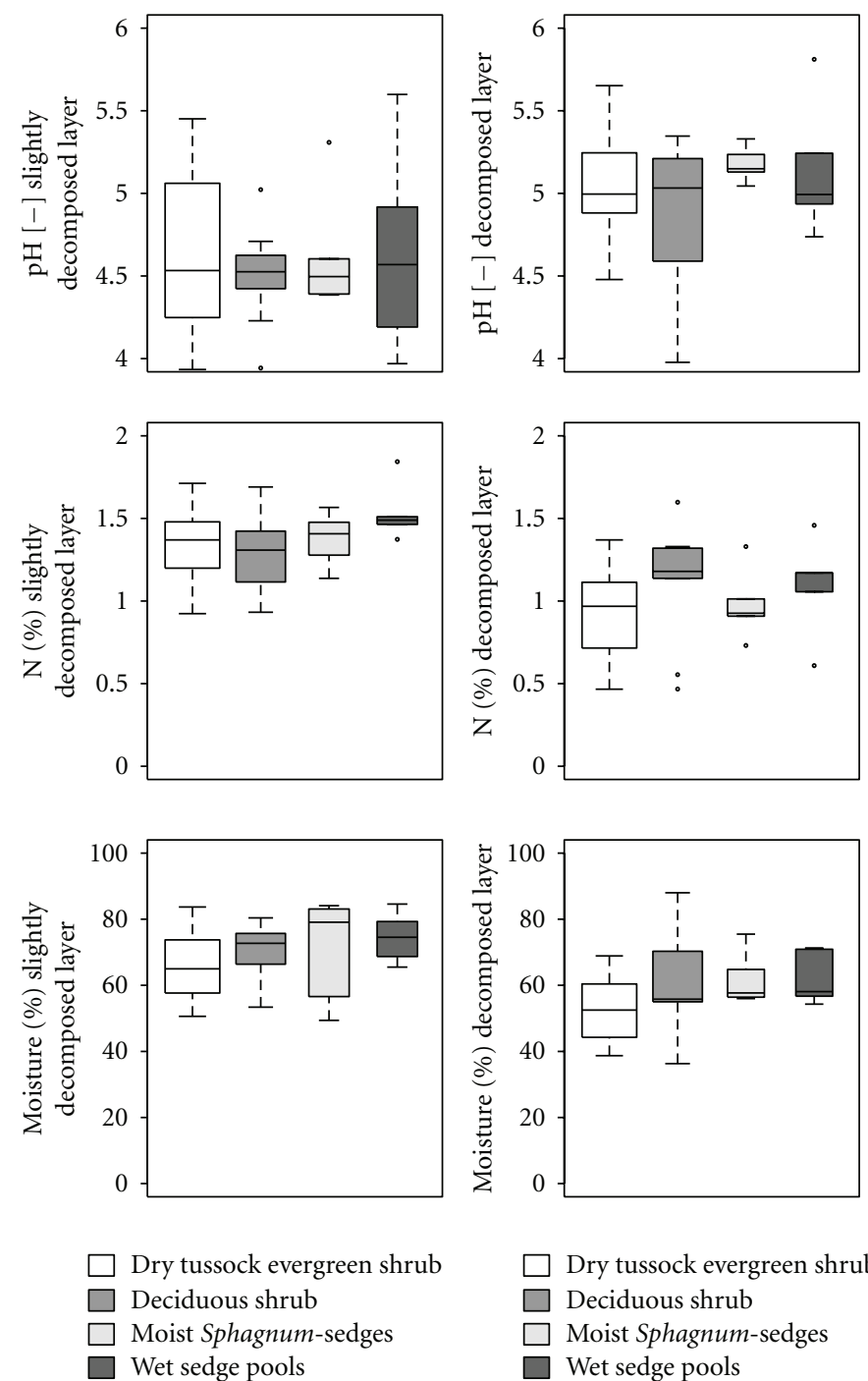
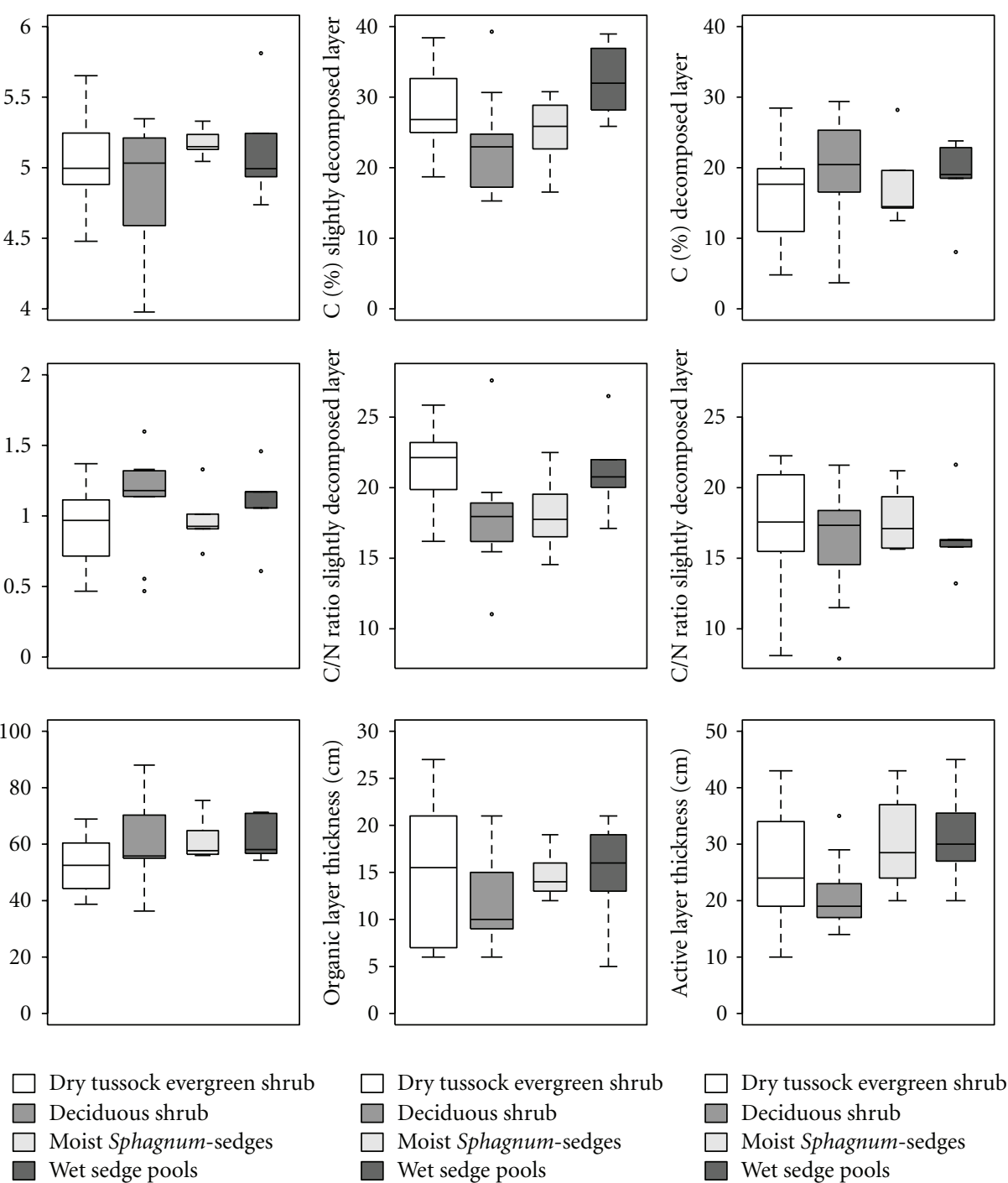

FiguRE 7: Boxplots of the predicted soil properties for the four vegetation classes.

The total $\mathrm{N}$ content in the slightly decomposed layer does not show large variation between the different vegetation classes. Remarkable is the low variation within the wet sedge vegetation class. The total $\mathrm{N}$ content of the decomposed layer is generally about $0.5 \%$ lower than for the slightly decomposed layer, although the difference is small for the deciduous shrub vegetation class. The $\mathrm{C} / \mathrm{N}$ ratio is overall rather high, indicating that the organic material in the soil does not contain large amounts of humus. This is mainly the case for the dry tussock evergreen shrub class, which consists of dense graminoid species (Eriophorum vaginatum) with low evergreen shrubs with dense roots and relatively large amounts of litter.

Plots dominated by deciduous shrubs show a lower active layer thickness (ALT), which corresponds with the results from a shrub removal experiment by Blok et al. [46], showing that shrubs can reduce energy transfer to the soil by shading the soil surface and thus can reduce ALT. Sphagnum and sedge-dominated wet areas show a higher ALT, probably due to the high soil moisture levels, increasing soil thermal conductivity. Strong relations between vegetation composition and ALT have, for example, been shown in a largescale study conducted in Alaska, where strong differences in ALT were observed between vegetation types along a gradient from shrub-dominated to barren tundra [47].

As expected, the soil moisture content is highest for the wet vegetation classes (Sphagnum sedge and wet sedge pools), but the difference in soil moisture content under the other vegetation types is not that large, probably due to the fact that we sampled early summer. As a result, soil moisture content is high $(>40 \%)$ for most samples, under all vegetation types, which prohibits a good estimation of soil properties by in situ reflectance measurements.

3.5. Implications for Spatially Continuous Mapping of Soil Properties. The relationships between plant species composition and soil properties allow qualitative estimations for $\mathrm{C}$ and $\mathrm{N}$ in the different organic layers, due to the limited variation within the vegetation classes, but the relationships are not distinctive enough to be used as a proxy for 


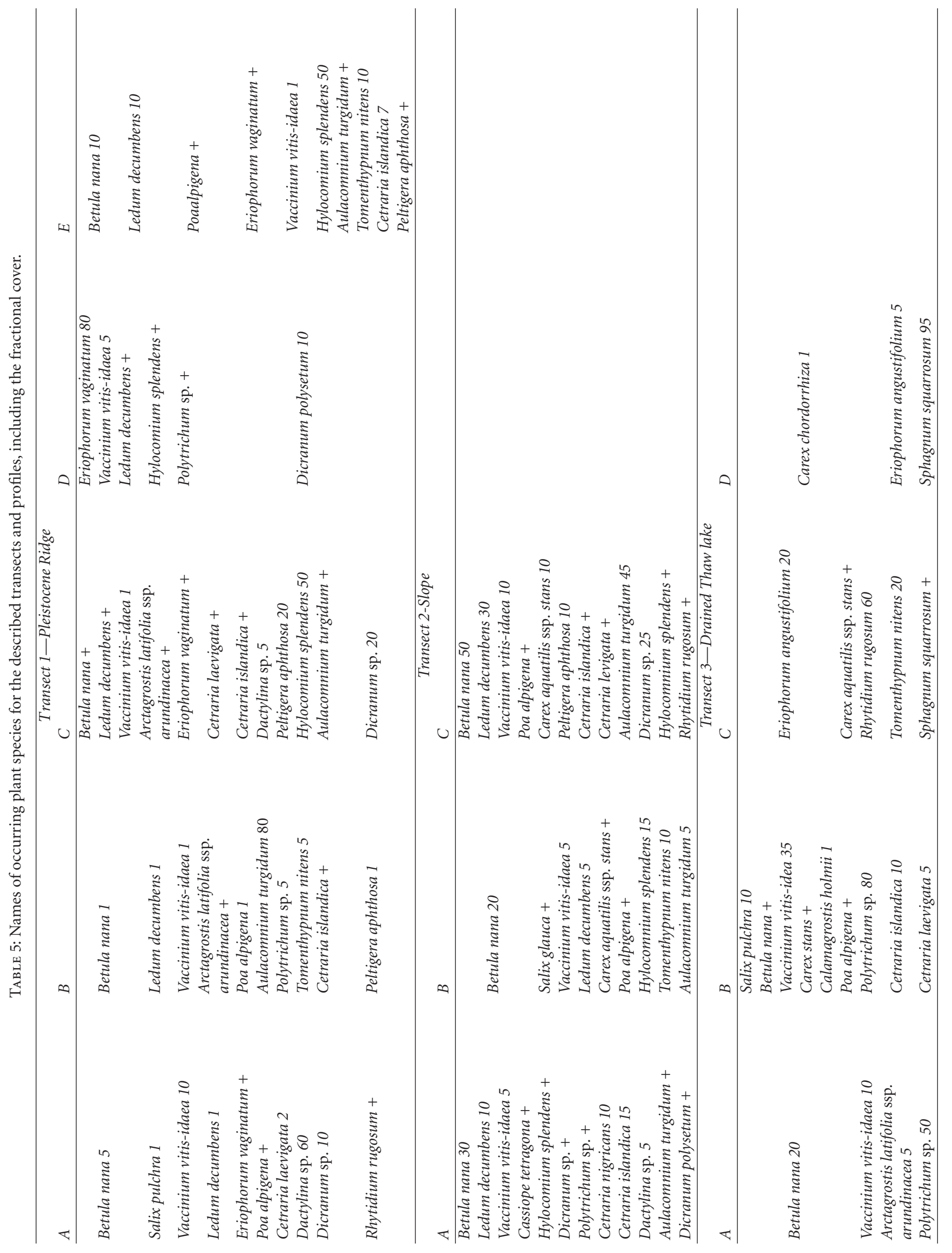


quantitative estimates. Knowing the vegetation type, it can be determined if a high or low $\mathrm{C}$ and $\mathrm{N}$ can be expected. Concerning the $\mathrm{pH}$, qualitative estimation will be possible for some vegetation classes for some horizons. Especially for moist Sphagnum sedges, the range in $\mathrm{pH}$ is small for both the slightly decomposed and the decomposed organic layer.

The fact that the presence of certain plant species is related to the soil properties opens possibilities for application of vegetation spectroscopy and remote sensing. Field reflectance measurements can be used to estimate presence and fractional cover of different species, for example, by using spectral unmixing techniques [48]. Given the large spatial variation in plant species composition, the use of air- or spaceborne remote sensing data requires both a high spatial $(<1 \mathrm{~m})$ and spectral resolution. Nowadays, these can only be acquired from airborne platforms. Next to this, cokriging techniques, using the vegetation as proxy variable in combination with a well-designed spatial sampling strategy, may offer possibilities for spatial mapping of soil properties in the arctic tundra. The presented spectral methods do allow fast and cheap intensive measurement of the soil properties in our study area. Possibilities to map vegetation classes comparable to the twinspan classification have to be investigated, since twinspan determines class assignments based on occurrence and quantity of individual species, which is practically impossible to determine with remote sensing data.

\section{Conclusions}

The presented results show that reflectance spectroscopy can be used for fast quantification of multiple soil properties in the Siberian tundra, although drying of the soil samples is required before measuring reflectance. As such, it can be a useful tool to achieve a higher sampling density for soil properties in tundra ecosystems, where logistics limit the collection and chemical analysis of a large number of samples. In situ reflectance spectroscopy can be used to determine total C. Soil properties show large variation over short distances, requiring intensive sampling to achieve good regional estimates of, for example, carbon stocks. To allow good estimates of carbon stocks in the area, it is important to increase maximum sampling depth and determine bulk density for each sample. Because of the relation between vegetation species and soil properties, plant species composition can be used to give a qualitative indication about the soil properties below the surface.

\section{Appendix}

For more details see Table 5.

\section{Acknowledgment}

The authors would like to thank Alexander Kononov of the Institute of Biological Problems of the Cryolithozone, Yakutsk, for assistance in the logistics.

\section{References}

[1] IPCC, "Climate change 2007: the physical science basis," in Contribution of Working Group I to the Fourth Assessment
Report of the Intergovernmental Panel on Climate Change, S. Solomon, D. Qin, M. Manning et al., Eds., p. 996, Cambridge University Press, Cambridge, UK, 2007.

[2] E. Post, M. C. Forchhammer, M. S. Bret-Harte et al., "Ecological dynamics across the arctic associated with recent climate change," Science, vol. 325, no. 5946, pp. 1355-1358, 2009.

[3] ACIA, in Arctic Climate Impact Assessment, Impacts of a Warming Arctic, V. M. Kattsov and E. Källén, Eds., pp. 99-150, Cambridge University Press, Cambridge, UK, 2004.

[4] C. D. Koven, B. Ringeval, P. Friedlingstein et al., "Permafrost carbon-climate feedbacks accelerate global warming," Proceedings of the National Academy of Sciences of the United States of America, vol. 108, no. 36, pp. 14769-14774, 2011.

[5] V. E. Romanovsky, D. S. Drozdov, N. G. Oberman et al., "Thermal state of permafrost in Russia," Permafrost and Periglacial Processes, vol. 21, no. 2, pp. 136-155, 2010.

[6] D. Blok, M. M. P. D. Heijmans, G. Schaepman-Strub, A. V. Kononov, T. C. Maximov, and F. Berendse, "Shrub expansion may reduce summer permafrost thaw in Siberian tundra," Global Change Biology, vol. 16, no. 4, pp. 1296-1305, 2010.

[7] E. A. G. Schuur, J. G. Vogel, K. G. Crummer, H. Lee, J. O. Sickman, and T. E. Osterkamp, "The effect of permafrost thaw on old carbon release and net carbon exchange from tundra," Nature, vol. 459, no. 7246, pp. 556-559, 2009.

[8] N. S. Zimov, S. A. Zimov, A. E. Zimová, G. M. Zimová, V. I. Chuprynin, and F. S. Chapin, "Carbon storage in permafrost and soils of the mammoth tundra-steppe biome: role in the global carbon budget," Geophysical Research Letters, vol. 36, no. 2, Article ID L02502, 6 pages, 2009.

[9] E. Dorrepaal, S. Toet, R. S. P. Van Logtestijn et al., "Carbon respiration from subsurface peat accelerated by climate warming in the subarctic," Nature, vol. 460, no. 7255, pp. 616-619, 2009.

[10] R. T. Conant, M. G. Ryan, G. I. Ågren et al., “Temperature and soil organic matter decomposition rates-synthesis of current knowledge and a way forward," Global Change Biology, vol. 17, no. 11, pp. 3392-3404, 2011.

[11] W. D. Billings, J. O. Luken, D. A. Mortensen, and K. M. Peterson, "Arctic tundra: a source or sink for atmospheric carbon dioxide in a changing environment?" Oecologia, vol. 53, no. 1, pp. 7-11, 1982.

[12] W. D. Billings, J. O. Luken, D. A. Mortensen, and K. M. Peterson, "Increasing atmospheric carbon dioxide: possible effects on arctic tundra," Oecologia, vol. 58, no. 3, pp. 286-289, 1983.

[13] S. E. Hobbie and L. Gough, "Litter decomposition in moist acidic and non-acidic tundra with different glacial histories," Oecologia, vol. 140, no. 1, pp. 113-124, 2004.

[14] S. E. Hobbie, "Temperature and plant species control over litter decomposition in Alaskan tundra," Ecological Monographs, vol. 66, no. 4, pp. 503-522, 1996.

[15] J. H. C. Cornelissen, P. M. Van Bodegom, R. Aerts et al., "Global negative vegetation feedback to climate warming responses of leaf litter decomposition rates in cold biomes," Ecology Letters, vol. 10, no. 7, pp. 619-627, 2007.

[16] L. Gough, G. R. Shaver, J. Carroll, D. L. Royer, and J. A. Laundre, "Vascular plant species richness in Alaskan arctic tundra: the importance of soil pH," Journal of Ecology, vol. 88, no. 1, pp. 54-66, 2000.

[17] F. S. Chapin, G. R. Shaver, A. E. Giblin, K. J. Nadelhoffer, and J. A. Laundre, "Responses of Arctic tundra to experimental and observed changes in climate," Ecology, vol. 76, no. 3, pp. 694711, 1995. 
[18] M. D. Walker, C. H. Wahren, R. D. Hollister et al., "Plant community responses to experimental warming across the tundra biome," Proceedings of the National Academy of Sciences of the United States of America, vol. 103, no. 5, pp. 1342-1346, 2006.

[19] D. Blok, G. Schaepman-Strub, H. Bartholomeus, M. M. P. D. Heijmans, T. C. Maximov, and F. Berendse, "The response of Arctic vegetation to the summer climate: relation between shrub cover, NDVI, surface albedo and temperature," Environmental Research Letters, vol. 6, no. 3, Article ID 035502, 2011.

[20] F. S. Chapin, M. Sturm, M. C. Serreze et al., "Role of landsurface changes in arctic summer warming," Science, vol. 310, no. 5748, pp. 657-660, 2005.

[21] C. W. Chang, D. A. Laird, M. J. Mausbach, and C. R. Hurburgh, "Near-infrared reflectance spectroscopy-principal components regression analyses of soil properties," Soil Science Society of America Journal, vol. 65, no. 2, pp. 480-490, 2001.

[22] R. A. Viscarra Rossel, D. J. J. Walvoort, A. B. McBratney, L. J. Janik, and J. O. Skjemstad, "Visible, near infrared, mid infrared or combined diffuse reflectance spectroscopy for simultaneous assessment of various soil properties," Geoderma, vol. 131, no. 1-2, pp. 59-75, 2006.

[23] A. Stevens, B. van Wesemael, H. Bartholomeus, D. Rosillon, B. Tychon, and E. Ben-Dor, "Laboratory, field and airborne spectroscopy for monitoring organic carbon content in agricultural soils," Geoderma, vol. 144, no. 1-2, pp. 395-404, 2008.

[24] B. Stenberg, R. A. Viscarra Rossel, A. M. Mouazen, and J. Wetterlind, "Visible and Near Infrared Spectroscopy in Soil Science," Advances in Agronomy, vol. 107, pp. 163-215, 2010.

[25] M. K. Van Der Molen, J. Van Huissteden, F. J. W. Parmentier et al., "The growing season greenhouse gas balance of a continental tundra site in the Indigirka lowlands, NE Siberia," Biogeosciences, vol. 4, no. 6, pp. 985-1003, 2007.

[26] D. A. Walker, M. K. Reynolds, F. J. A. Daniëls et al., "The Circumpolar Arctic vegetation map," Journal of Vegetation Science, vol. 16, no. 3, pp. 267-282, 2005.

[27] P. H. Fidêncio, R. J. Poppi, J. C. De Andrade, and H. Cantarella, "Determination of organic matter in soil using near-infrared spectroscopy and partial least squares regression," Communications in Soil Science and Plant Analysis, vol. 33, no. 9-10, pp. 1607-1615, 2002.

[28] T. Udelhoven, C. Emmerling, and T. Jarmer, "Quantitative analysis of soil chemical properties with diffuse reflectance spectrometry and partial least-square regression: a feasibility study," Plant and Soil, vol. 251, no. 2, pp. 319-329, 2003.

[29] H. Bartholomeus, L. Kooistra, A. Stevens et al., "Soil Organic Carbon mapping of partially vegetated agricultural fields with imaging spectroscopy," International Journal of Applied Earth Observation and Geoinformation, vol. 13, no. 1, pp. 81-88, 2011.

[30] R. A. Viscarra Rossel, "ParLeS: software for chemometric analysis of spectroscopic data," Chemometrics and Intelligent Laboratory Systems, vol. 90, no. 1, pp. 72-83, 2008.

[31] P. J. Curran, "Remote sensing of foliar chemistry," Remote Sensing of Environment, vol. 30, no. 3, pp. 271-278, 1989.

[32] R. Ihaka and R. Gentleman, "R: a language for data analysis and graphics," Journal of Computational and Graphical Statistics, vol. 5, no. 3, pp. 299-314, 1996.

[33] C. W. Chang and D. A. Laird, "Near-infrared reflectance spectroscopic analysis of soil C and N," Soil Science, vol. 167, no. 2, pp. 110-116, 2002.

[34] M. O. Hill and P. Šmilauer, TWINSPAN for Windows Version 2.3, Centre for Ecology \& Hydrology and University of South Bohemia, Huntingdon, UK, 2005.
[35] D. Blok, Shrubs in the Cold: Interactions between Vegetation, Permafrost and Climate in Siberian Tundra, Wageningen University, Wageningen, The Netherlands, 2011.

[36] S. A. Zimov, S. P. Davydov, G. M. Zimova et al., "Permafrost carbon: stock and decomposability of a globally significant carbon pool," Geophysical Research Letters, vol. 33, no. 20, Article ID L20502, 5 pages, 2006.

[37] E. Ben-Dor, "Quantitative remote sensing of soil properties," Advances in Agronomy, vol. 75, pp. 173-243, 2002.

[38] M. Knadel, A. Thomsen, and M. H. Greve, "Multisensor onthe-go mapping of soil organic carbon content," Soil Science Society of America Journal, vol. 75, no. 5, pp. 1799-1806, 2011.

[39] G. J. Michaelson, C. L. Ping, and J. M. Kimble, "Carbon storage and distribution in tundra soils of Arctic Alaska, U.S.A," Arctic and Alpine Research, vol. 28, no. 4, pp. 414-424, 1996.

[40] H. Lee, E. A. G. Schuur, K. S. Inglett, M. Lavoie, and J. P. Chanton, "The rate of permafrost carbon release under aerobic and anaerobic conditions and its potential effects on climate," Global Change Biology, vol. 18, no. 2, pp. 515-527, 2012.

[41] P. Dunfield, R. knowles, R. Dumont, and T. R. Moore, "Methane production and consumption in temperate and subarctic peat soils: response to temperature and $\mathrm{pH}$," Soil Biology and Biochemistry, vol. 25, no. 3, pp. 321-326, 1993.

[42] R. T. Williams and R. L. Crawford, "Methanogenic Bacteria, including an acid-tolerant strain, from peatlands," Applied and Environmental Microbiology, vol. 50, no. 6, pp. 1542-1544, 1985.

[43] M. S. Bret-Harte, G. R. Shaver, J. P. Zoerner et al., "Developmental plasticity allows betula nana to dominate tundra subjected to an altered environment," Ecology, vol. 82, no. 1, pp. 18-32, 2001.

[44] D. Blok, U. Sass-Klaassen, G. Schaepman-Strub, M. M. P. D. Heijmans, P. Sauren, and F. Berendse, "What are the main climate drivers for shrub growth in Northeastern Siberian tundra?" Biogeosciences, vol. 8, no. 5, pp. 1169-1179, 2011.

[45] I. H. Myers-Smith, B. C. Forbes, M. Wilmking et al., "Shrub expansion in tundra ecosystems: dynamics, impacts and research priorities," Environmental Research Letters, vol. 6, no. 4, Article ID 045509, 2011.

[46] D. Blok, G. Schaepman-Strub, M. Heijmans et al., Climate Change Effects on Vegetation in Northeastern Siberian TundraHow Does Shrub Growth Relate to Local Climate and What Are Potential Effects of Shurb Expansion on Permafrost Thawing? EGU General Assembly, Vienna, Austria, 2010.

[47] F. E. Nelson, N. I. Shiklomanov, G. R. Mueller, K. M. Hinkel, D. A. Walker, and J. G. Bockheim, "Estimating active-layer thickness over a large region: Kuparuk river basin, Alaska, U.S.A," Arctic and Alpine Research, vol. 29, no. 4, pp. 367-378, 1997.

[48] G. Schaepman-Strub, J. Limpens, M. Menken, H. M. Bartholomeus, and M. E. Schaepman, "Towards spatial assessment of carbon sequestration in peatlands: spectroscopy based estimation of fractional cover of three plant functional types," Biogeosciences, vol. 6, no. 2, pp. 275-284, 2009. 

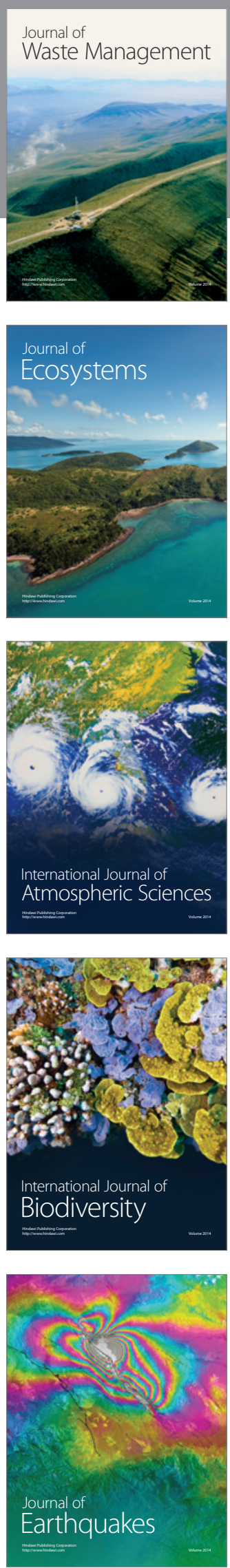
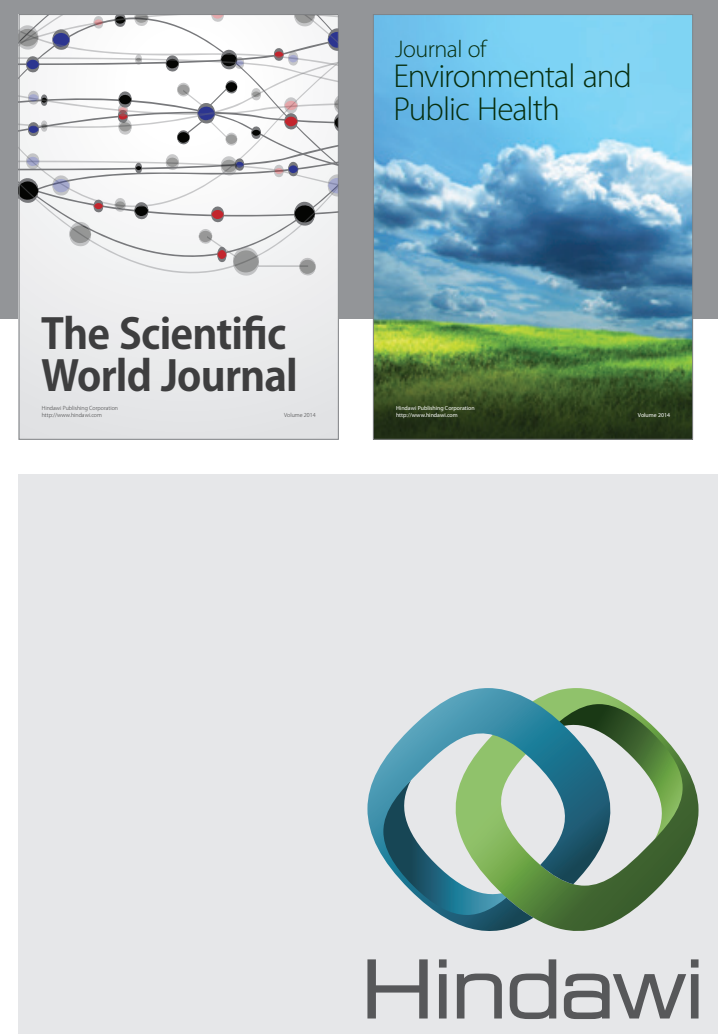

Submit your manuscripts at

http://www.hindawi.com
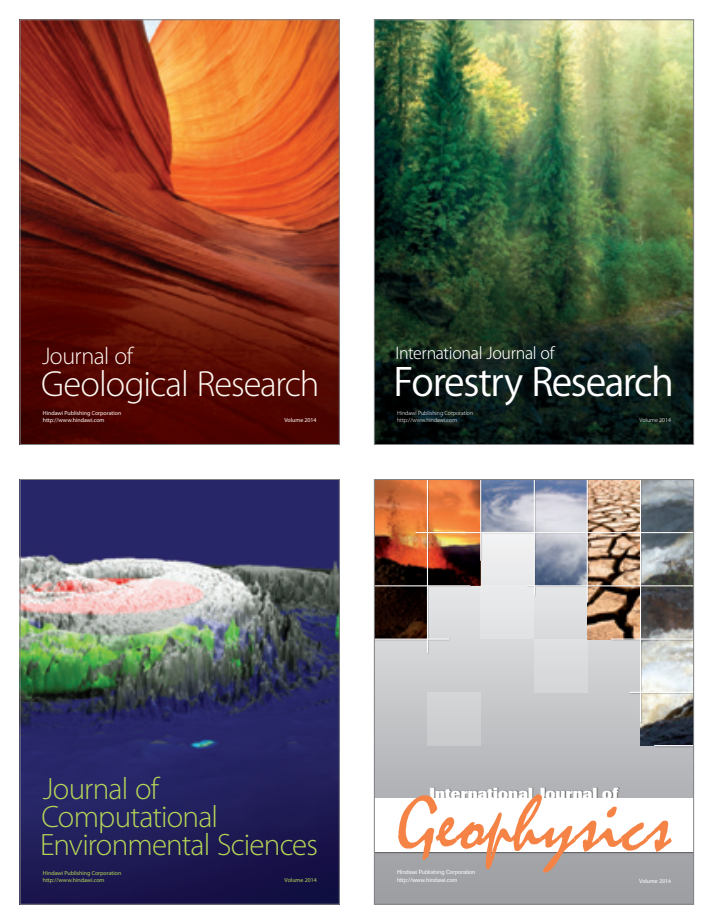
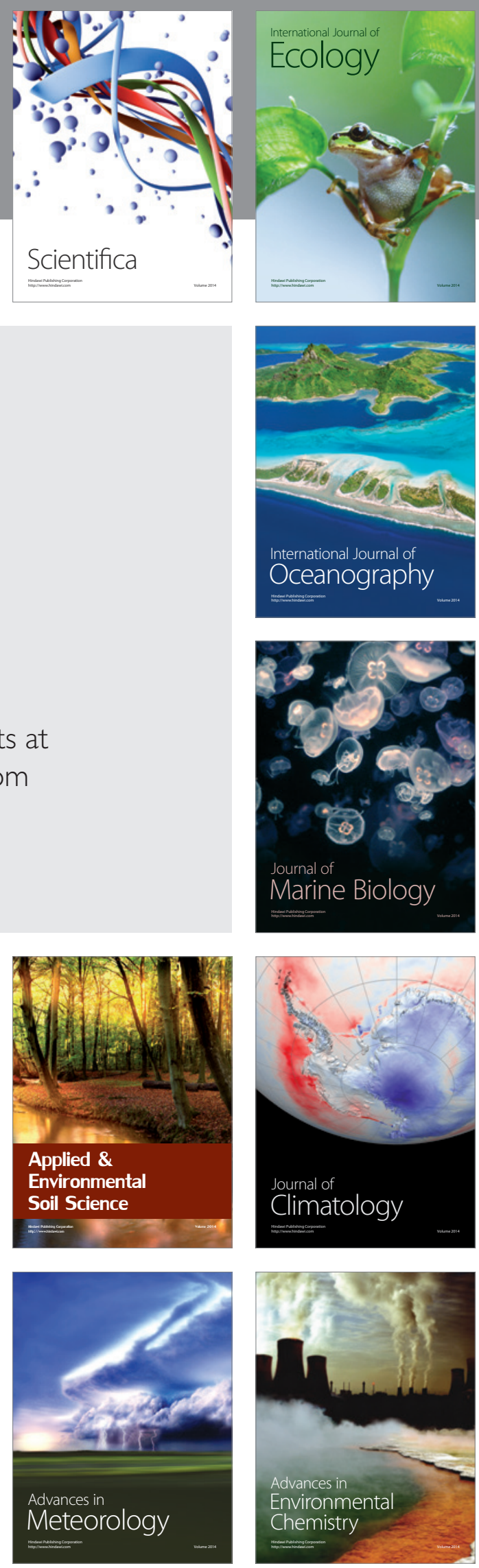